\title{
A numerical parametric study on the efficiency of prestressed geogrid reinforced soil
}

\author{
Soukat Kumar Das ${ }^{1,}{ }^{*}$ and N. K. Samadhiya ${ }^{2}$ \\ ${ }^{1}$ Research Scholar, Department of Civil Engineering, Indian Institute of Technology, Kanpur, Uttar Pradesh, India, 208016 \\ ${ }^{2}$ Professor, Department of Civil Engineering, Indian Institute of Technology, Roorkee, Uttarakhand, India, 247667
}

\begin{abstract}
Prestressing geosynthetics offers a rapid and safe method of improving the poor ground conditions. This paper aims to find out the effect of prestressing the geogrid layer on load bearing and settlement performance. This study also takes into account the impact of the size, depth of placement and the adjacency of footing, for unreinforced (UR), geogrid reinforced (GR) and prestressed geogrid reinforced (PGR) soil on the load-bearing and the settlement characteristics by using the finite element program Plaxis 3D. Based on numerical simulation, it appears that PGR soil can enhance the bearing pressure of the UR soil by almost $500 \%$ and reduced the settlement by nearly $88 \%$ by reducing the energy consumption. The footing placed at higher depths for PGR soil gives better performance as compared to GR soil. Moreover, placing two adjacent square footing increases the interference zone of PGR soil by $67 \%$ as compared to UR soil. This method can be instrumental in reducing the total input energy requirement to achieve a certain settlement during placement of shallow foundation for various important structures while being economic simultaneously.
\end{abstract}

\section{Introduction}

With brisk population growth and industrialization, it has become almost inevitable that the availability of suitable ground conditions is going down rapidly. Foundations resting on weak and unstable soils presents a severe stability threat. There are various ground improvement techniques available for improving the marginal ground today. However, the use of geosynthetics is found to be a cost-effective reinforcement system and leads to better performance of shallow foundations. In the last few decades, numerous studies have been conducted to study the behavior of reinforced soil foundation system (RSFS). Various factors that affect the performance of RSFS include 1) type of geosynthetic layer [1,2]; 2) number of geosynthetic layers [3-5]; 3) depth of placement of first layer of reinforcement below the footing [6]; 4) type and placement of the fill [7-9] and others.

From the past studies, it has been observed that the tension in the geosynthetic layer is mobilized after undergoing considerable deformation $[2,10,11]$. However, this small deformation may hinder the utility of essential structures like railway tracks, pavements, airfields, embankments etc. [10-12]. Moreover, it requires added amount of input energy during installation beneath foundations. Prestressing the geosynthetics, particularly geotextile and geogrid significantly overcome the problem of undergoing excessive settlement to mobilize the tension within it [13-15].

Shukla and Chandra (1995) [17] conducted pioneering work while studying the prestressed geotextile reinforced soil by solving the governing differential equation using finite difference method. Later, other researchers $[6,18,19]$ have also studied the effects of prestressing on different types of soils experimentally as well as numerically by using commercially available finite element packages. Lackner et al., (2013) [20] conducted an interesting study on the potential of various prestressing methods by using the particle image velocimetry (PIV) analysis of the deforming soil mass. The Huesker geosynthetics of Germany has designed a special placing beam to apply a known amount of prestress in the geogrid (Huesker Synthetic, 2004) [21]. Later on, Chew et al. (2005) [22] have undertaken successful implementation of prestressed geotextile in the field, applying $3.5 \%$ pretensioning across the geotextile for the stabilization of unpaved army road in Singapore. In the present study, attempts have been made to analyze the effect of prestressed geogrid layers kept below the square footing and comparing the results of unreinforced (UR), geogrid reinforced (GR) and prestressed geogrid reinforced (PGR) soil for energy consumption for a prescribed settlement and other parameters. This study also takes into account the different aspects related to the practical relevance of prestressing in the field like the effects of the depth of the footing, size of the footing and the interference of two square footings placed nearby on its load-bearing and the settlement characteristics.

\section{Model considerations}

Numerical analysis has been performed to understand the performance of square foundation resting on prestressed geogrid reinforced soil using finite element package

\footnotetext{
* Corresponding author: soukat@iitk.ac.in
} 
Plaxis 3D (Brinkgreve et al., 2013) [23]. The present study examines the condition where a square footing of size $100 \mathrm{~mm} * 100 \mathrm{~mm} * 10 \mathrm{~mm}$, is placed over a twolayered soil system. The adopted dimensions are large enough to avoid any boundary effect which is checked at the beginning of analyses. The top layer soil consists of well-graded medium-sized sand laid above the weak soil layer (SP-ML). The size of the tank used in the analysis is the same as mentioned by Aswathy et al. (2013) [25] i.e. $0.75 \mathrm{~m} \mathrm{x} 0.75 \mathrm{~m}$ in plan and $1 \mathrm{~m}$ in height. Whereas, for studying the effect of interference of adjacent footing, the plan area of the tank increased to $2 \mathrm{~m} \times 2 \mathrm{~m}$ to get rid of the boundary effect of the tank. The weak soil layer is known as the 'Shedi' soil, which is found on the West coast (Konkan cost) of India. This soil poses serious construction problems on saturation since in this condition, it behaves like a soft soil. The properties of sand, Shedi soil and geogrid layer used in the present study have been obtained from Aswathy et al. (2013) [25] and are listed in Tables 1,2 and 3 respectively. Please note the high cohesion of the weak soil is due to presence of high fine content in the Shedi soil.

Table 1. Properties of sand [25]

\begin{tabular}{|c|c|}
\hline Property & Value \\
\hline Specific gravity & 2.61 \\
\hline Effective grain size, $\mathrm{D}_{10}(\mathrm{~mm})$ & 0.50 \\
\hline $\mathrm{D}_{30}(\mathrm{~mm})$ & 0.80 \\
\hline $\mathrm{D}_{60}(\mathrm{~mm})$ & 1.30 \\
\hline Coefficient of uniformity, $\mathrm{C}_{\mathrm{u}}$ & 2.60 \\
\hline Coefficient of curvature, $\mathrm{C}_{\mathrm{c}}$ & 1.00 \\
\hline Angle of internal friction $(\phi)$ (Degrees) & 40.0 \\
\hline
\end{tabular}

Table 2. Properties of weak soil [25]

\begin{tabular}{|c|c|}
\hline Property & Value \\
\hline Specific gravity & 2.32 \\
\hline Maximum dry unit weight $\left(\mathrm{kN} / \mathrm{m}^{3}\right)$ & 17.5 \\
\hline Liquid limit $(\%)$ & 37.0 \\
\hline Plastic limit $(\%)$ & 33.0 \\
\hline Cohesion $\left(\mathrm{kN} / \mathrm{m}^{2}\right)$ & 26.0 \\
\hline Angle of friction $(\phi)$ (Degrees) & 20.0 \\
\hline USCS Classification & SP-ML \\
\hline
\end{tabular}

Table 3. Properties of geogrid [25]

\begin{tabular}{|c|c|}
\hline Specifications & Remarks \\
\hline Form & Sheet \\
\hline Width $(\mathrm{m})$ & 2 \\
\hline Mesh aperture size (mm) & $8 \times 6$ \\
\hline Mesh thickness (mm) & 3.3 \\
\hline Polymer & HDPE \\
\hline Maximum tensile strength (kN/m) & 7.68 \\
\hline Extension at maximum load (\%) & 20.20 \\
\hline
\end{tabular}

The Poisson's ratio used in the study is 0.25 for all the cases. The grain size distributions for the two types of soil are shown in Fig. 1. The width of the geogrid layer reported in the literature lies between $3 \mathrm{~B}$ and $5 \mathrm{~B}$. Therefore, $5 \mathrm{~B}$ width is adopted here (where $\mathrm{B}$ is the width of the footing i.e. $0.1 \mathrm{~m}$ ). The geogrid layer has been placed at a depth of $0.5 \mathrm{~B}$ i.e. $0.05 \mathrm{~m}$ from the footing surface as the optimum depth of the geogrid layer lies between $0.2 \mathrm{~B}-0.5 \mathrm{~B}$ [26]. A schematic diagram for the numerical analyses is shown in Fig. 2.

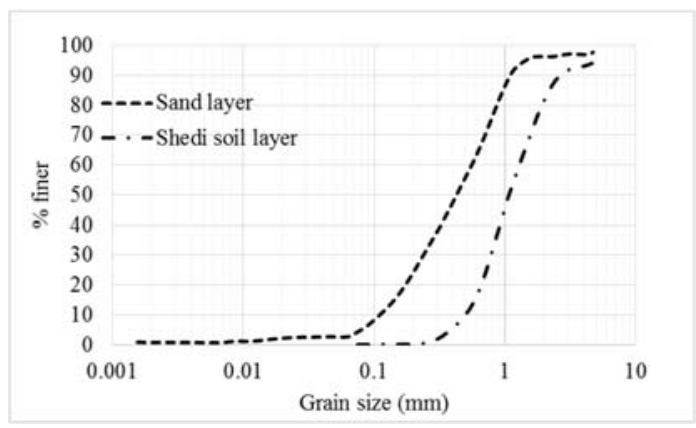

Fig. 1. Particle size distribution of sand and weak soil used

The depth of the strong granular bed over the weak soil layer has been taken to be $2 \mathrm{~B}$ for all the cases as it has produced the best results in the study conducted in the referred paper [27]. The prestressing force applied in the present study is $3 \%$ of the maximum tensile strength of the geogrid layer. The prestress is used both in $\mathrm{X}$ and $\mathrm{Y}$ direction as biaxial prestressing is found to be more effective [27].

\subsection{Finite element modelling}

Plaxis 3D, a 3-dimensional finite element software package, was used in this study. This software is often used for the analysis of deformation, groundwater, and slope stability problems in geotechnical engineering. The dimension of the tank is such that it has no boundary effect on the deformation of the footing under the action of loading. The model tank is horizontally fixed on the vertical sides, and full fixity on the base is assumed as a deformation boundary condition. The footing has been placed centrally for the analysis.

The geogrid layer used in the study is modelled as a slender structure with an axial stiffness $(7.68 \mathrm{kN} / \mathrm{m})$ having no bending stiffness. Moreover, it can only sustain tensile forces and no compression. The geogrid elements are automatically defined with 6-node triangular surface elements. The interaction between the soil and geogrid is modelled using interface elements. An interface element is composed of 12-node interface elements with an imaginary thick-ness (zero thickness), used to define the material properties of the interface $\left(\mathrm{R}_{\text {inter }}\right)$. The $\mathrm{R}_{\text {inter }}$ adopted in the study is 1 , which indicates that the strength of the interface is the same concerning the strength in the surrounding soil. Two interfaces at the top and at the bottom of the geogrid layer have been provided for better interaction with the granular sand layer.

Both the type of soils used in the study has been modelled using the Mohr-Coulomb failure model, which is a linearly-elastic perfectly-plastic model and requires a total of five parameters (two stiffness and three strength parameters) to model. These parameters have been obtained using basic geotechnical tests as mentioned by Aswathy et al. (2013) [25]. The prestressing force is 
applied by using fixed end anchors in both $\mathrm{X}$ and $\mathrm{Y}$ directions, which amounted to $3 \%$ of the maximum tensile strength of the geogrid layer, as mentioned earlier.

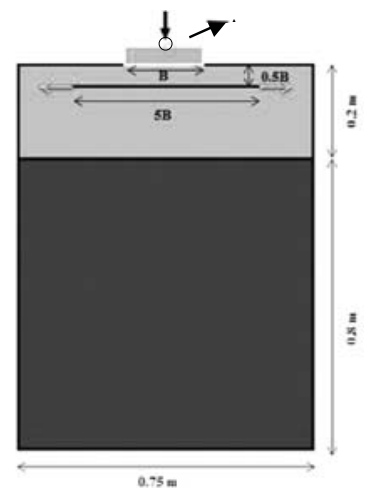

Figure 2. Schematic diagram of the test tank used for numerical analyses.

\subsection{Mesh generation and stage construction}

For performing the calculation, the geometry has to be divided into elements, and the combination of such elements is called finite element mesh. After defining the model geometry and assigning the material to both the soil layer and structural object, the 3D mesh is generated. The Plaxis 3D allows for a fully automatic generation of 3D finite element mesh, which is based on a system of horizontal and pseudo-horizontal planes in which 2D mesh is used. The basic soil elements of the 3D finite element mesh are 10-node tetrahedral elements. Coarse mesh analysis has been used for all the studies to get faster results. The mesh quality has also been checked so that no unwanted meshing remains in the model. The mesh generation has created around 20000 nodes in the total reinforced system. In order to make the analysis more realistic and robust, the stage construction process has been adopted for study (Fig. 3).

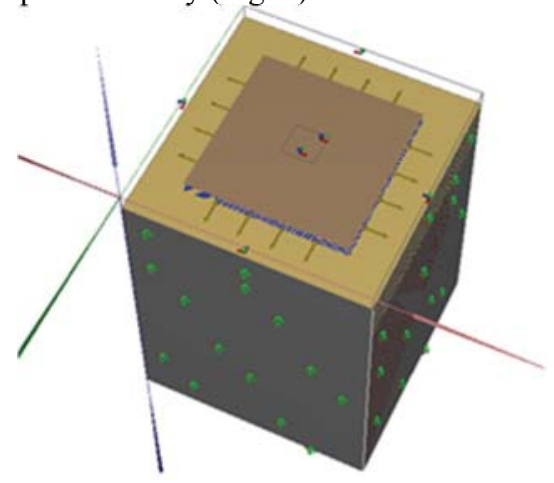

Figure 3. Mesh for simulation of staged construction process used for numerical analyses for placement of geogrid layer above weak soil

In the first stage, the weak soil is filled up to the predefined depth into the tank. In the next step, the sand is filled up to the level at which the geogrid layer is to be placed. The geogrid layer is then placed over the sand bed with the proper interface at the top and bottom of the geogrid membrane for GR soil. The prestressing force is applied to the geogrid layer for the PGR soil system. The rest of the granular soil is then poured over the geogrid layer. Finally, the footing with prescribed displacement is placed centrally at the top of the tank. This staged construction procedure is vital because the reinforcement should be prestressed before filling soil above it; otherwise, the friction between soil and reinforcement will prevent the elongation of reinforcement due to prestressing.

\subsection{Validation of the numerical model}

The validation of the numerical model plays a crucial role in any modelling analysis as it ascertains the feasibility of the model. In the present case, the numerical results are compared with the experimental results presented by Aswathy et al. (2013) [25]. The plots of settlement (s), normalized by the width of the square footing (B) vs. bearing pressure of UR, GR and PGR soil for laboratory analysis (denoted as Lab) conducted by Aswathy et al. (2013) [25] and the Plaxis 3D analysis are presented in Fig. 4. As we have not considered the ultimate bearing capacity of the soil, we have used the term 'bearing pressure' in order to find out the response of the soil system instead of bearing capacity for all the analyses.

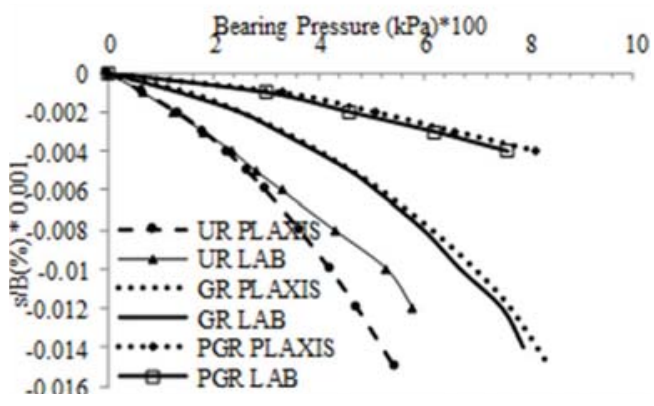

Figure 4. Normalized settlement vs. bearing pressure curves for comparison of laboratory [25] and numerical study of UR, GR, and PGR Soil.

It can easily be seen from the plot that the incorporation of prestressing force into the reinforced soil structures has tremendously enhanced the load-bearing potential of the reinforced soil system. The total settlement in the case of the unreinforced and geogrid reinforced soil is much higher than the prestressed sample due to increased stiffness with default parameters available in Plaxis 3D and the laboratory. The variable which has been used to express the improvement of bearing capacity has been denoted by Improvement Factor $(I F)[4]$.

Bearing pressure of geogrid reinforced or

$$
\begin{aligned}
& I F=\frac{\text { prestressed geogrid reinforced soil at a certain settlement }}{\text { Bearing pressure of unreinforced or }} \\
& \text { geogrid reinforced soil at the same settlement }
\end{aligned}
$$

The GR soil when compared with the UR soil, gave maximum $I F$ value as 2.4 for the present analysis whereas 
it gave a lesser value of 2.08 for the actual laboratory analysis as seen in Fig. 5.

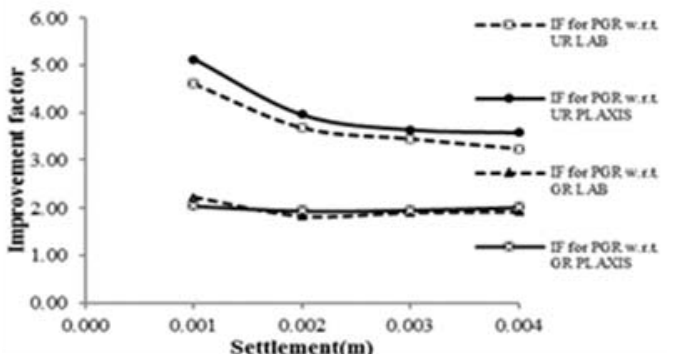

Figure 5. Improvement factor vs. settlement relationships for comparison of laboratory [25] and numerical study of UR, GR, and PGR Soil.

The improvement of the PGR soil as compared to GR soil is almost $200 \%$ throughout the settlement range. The reduction in Improvement factor at higher settlements may be due to the fact that the composite layer of geogrid is unable to diffuse the stresses induced due to the applied load on the footing. Apart from the increase in improvement load-bearing capacity, the settlement is also reduced to a great extent due to the introduction of prestressing into the reinforced soil system. For $100 \mathrm{kPa}$ bearing pressure, the GR soil improved the settlement by $67 \%$ for UR soil, whereas the PGR soil improved it by almost $89 \%$. The reduction in settlement of PGR soil with respect to GR soil has been around $66 \%$.

\section{Analysis and interpretation}

The main objective of the current research work is to understand the comparative load-deformation behavior of UR, GR, and PGR soil systems. The influence of depth of placement of footing, size of the footing and the interference of adjacent square footings placed nearby are examined by keeping the material properties of the softsoil, sand, and geogrid materials, the interface element types, the number of nodes and the mesh size as constant. In Plaxis 3D, we can incorporate force either employing prescribed force or prescribed displacement. In this case, the deformation caused by the rigid footing under the action of loading has been simulated using non-zero prescribed displacement (maximum 15\% of footing width) instead of modeling the footing itself. The maximum settlement is recorded at the point of maximum load intensity, i.e. at the point of load application. This point is shown as point A in Fig.2.

\subsection{Effect on energy efficiency}

The effect of prestressing on energy intake efficiency (energy required to attain a certain settlement) has been shown in this section. The total energy required to achieve $500 \mathrm{kPa}$ bearing pressure for the three types of samples have been calculated from Fig. 4 and shown as a bar diagram in Fig. 6. The energy required to attain $500 \mathrm{kPa}$ bearing pressure is highest for the UR sample $(26.75$
$\left.\mathrm{kJ} / \mathrm{m}^{3}\right)$, whereas it requires $84 \%$ lesser energy $(4.16 \mathrm{~kJ} /$ $\mathrm{m}^{3}$ ) to achieve the same bearing pressure for PGR soil. The energy requirement is undoubtedly less for the conventional GR soil, but it still needs more than double the energy as compared to PGR soil. The reason behind such findings may be attributed to the enhanced tension mobilization and the resultant increase in the stiffness of PGR soil as it requires lesser deformation to achieve a certain settlement and vice-versa. It also depicts the vast potential of using prestressing as an excellent energyefficient ground improvement tool for enhancing the bearing pressure and reducing the settlement at the same time.

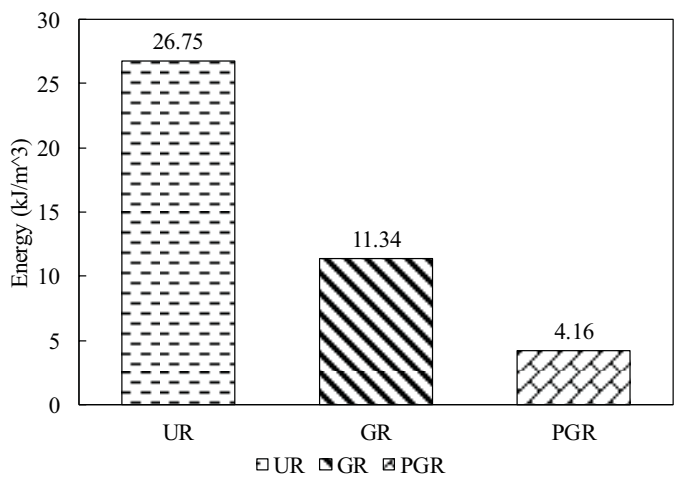

Fig. 6. Energy required to achieve $500 \mathrm{kPa}$ bearing pressure in UR, GR and PGR soil

\subsection{Effect of depth of footing}

It is a well-known fact that it is not always possible to place the foundation directly on to the surface due to many constructional restrictions. In these circumstances, the footing has to be placed at a certain depth below the ground surface. The depth, at which the footing is placed, plays a pivotal role in determining the load-bearing characteristics of the foundation. In the present case, two depths of footing (d) have been taken into account, which are $0.025 \mathrm{~m}$ and $0.04 \mathrm{~m}$. The depth is not increased further because of the geogrid layer is placed at a depth of $0.05 \mathrm{~m}$ from the surface of the tank, as mentioned earlier. The normalized settlement vs. bearing pressure curve for all the three types of soils viz. UR, GR and PGR soil have been plotted in Fig. 7. Here also, the improvement due to prestressing is quite easily visible. At the same time, it can be said that the load-bearing capacity has increased due to an increase in the depth of the footing from 0 to $0.04 \mathrm{~m}$ for all the three variants of soils.

From the figure, it can be said that for unreinforced soil, the increase in bearing capacity is more significant when the depth is increased up to $0.025 \mathrm{~m}$ from the surface and the depth $0.04 \mathrm{~m}$ gave a little improvement whereas for GR and PGR soil the increase in bearing pressure is almost uniform. The plot of improvement factor against the settlement has been plotted in Fig. 8. It can be seen that the prestressing effect is very much present for all the three depth of footing. For GR and PGR soil, the maximum improvement could be seen for $0.040 \mathrm{~m}$ of depth as expected. However, it is wise not to place the 
footing very near to the geogrid layer which could result in reduced bearing pressure due to the reduced mobilization of normal and shear stresses.

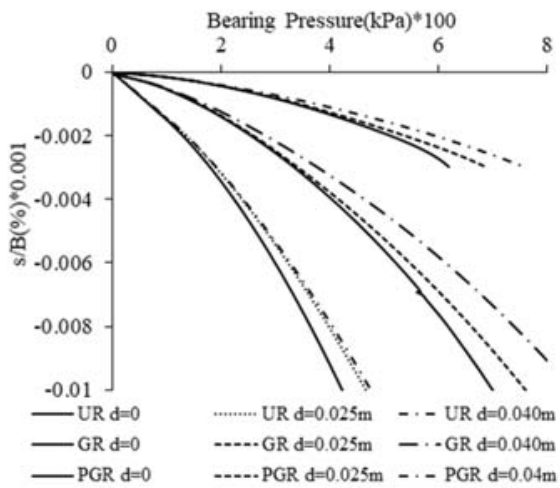

Figure 7. Normalized settlement vs. bearing pressure curves for UR GR PGR soil for different depths of footing.

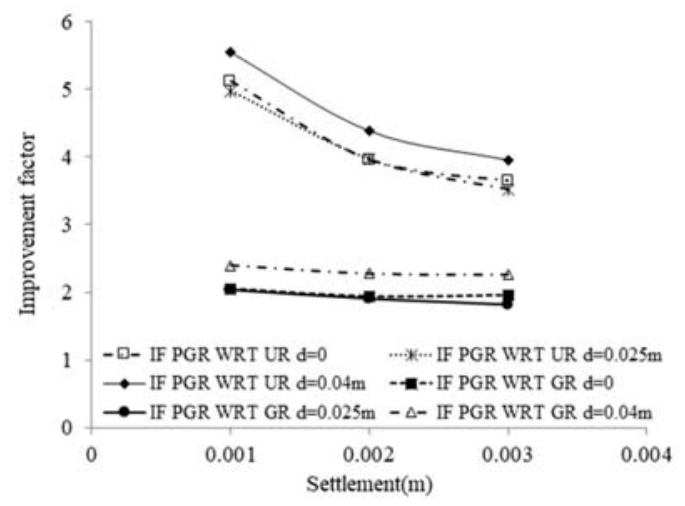

Figure 8. Improvement factors of PGR soil with respect to UR and GR soil vs. settlement curve for footing depth $0,0.025 \mathrm{~m}$ and $0.04 \mathrm{~m}$

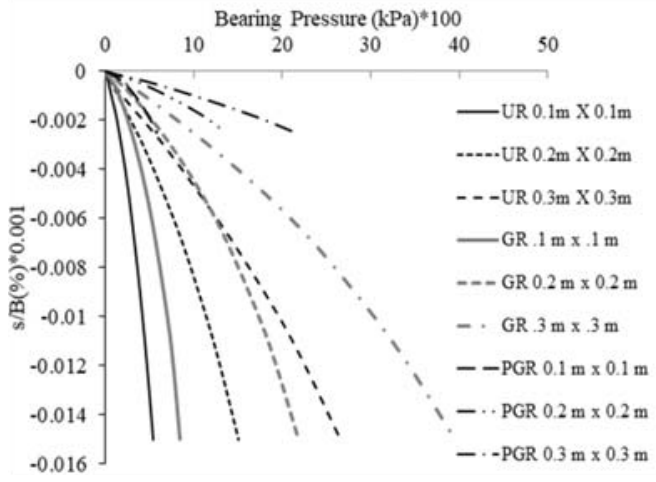

Fig. 9. Normalized settlement vs. bearing pressure curves for different size of footing in UR, GR and PGR soil

\subsection{Effect of size of the footing}

The effect of the size of the footing has been analyzed in the next segment of the study. Keeping in mind that footing size also has a significant influence on the response of the foundation, this parameter is studied while comparing for the three types of soils. For all the cases, square footings have been considered for analysis. A plot of normalized settlement vs. bearing pressure has been shown in Fig. 9 for UR, GR, and PGR soil. The sizes of the footing have been taken as $0.1 \mathrm{~m}, 0.2 \mathrm{~m}$, and $0.3 \mathrm{~m}$. The tank size has been increased to $2 \mathrm{~m} * 2 \mathrm{~m}$ in order to get rid of the boundary interference problem that has been checked prior to the selection of the footing sizes.

For all the three cases, the load-bearing pressure has increased due to an increase in the size of the footing. The maximum footing size i.e. $0.3 \mathrm{~m} \times 0.3 \mathrm{~m}$, gave the maximum amount of load-bearing pressure whereas $0.1 \mathrm{~m}$ $\mathrm{x} 0.1 \mathrm{~m}$, gave the minimum value. The settlement is found up to $15 \mathrm{~mm}$ for UR and GR soil and up to $2.5 \mathrm{~mm}$ for PGR soil. As the load-bearing pressure is directly related to the size of the footing, the increase in bearing pressure is justified. The increase due to prestressing is also a notable aspect of the current analysis. So it can be said that that PGR soil adds to the improvement due to footing size.

\subsection{Effect of interference of footing}

In many practical situations it is necessary to place footings near each other due to the scarcity of land as well as due to structural demands. However, placing one footing near to another footing always has an influence on the nearby footing. The third and final study which has been conducted here is the influence of adjacency of two interacting square foundations with increasing distance between the foundations. The distance between the square footing has been denoted as SFD (square footing distance) and has been varied in the range of $S F D=B, 2 B$, and $3 B$, where $\mathrm{B}$ is the width of the footing or $0.1 \mathrm{~m}$. The tank dimensions are taken here as $2 \mathrm{~m} * 2 \mathrm{~m}$ in view of addressing the issue of boundary interference with the increase in SFD in this case as well. The settlement could reach up to the imposed $15 \mathrm{~mm}$ mark for UR and GR soil but it could reach up to $2.5 \mathrm{~mm}$ for PGR soil due enhanced stiffness due to prestressing.

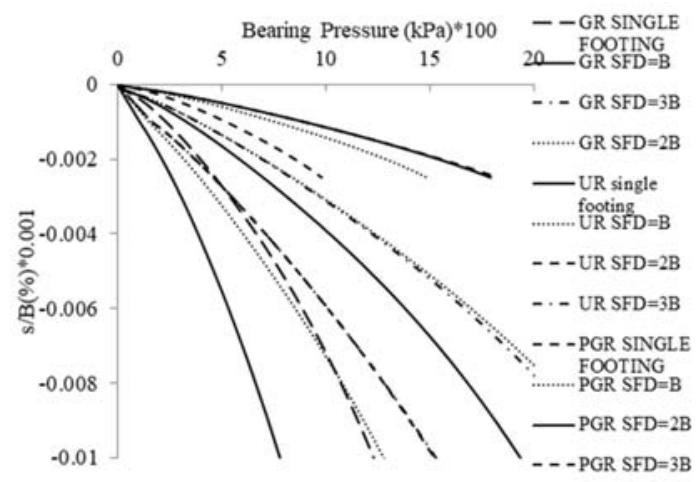

Fig. 10. Normalized settlement vs. bearing pressure curves for interfering square footing in UR, GR and PGR soil

The plot for the normalized settlements vs. bearing pressure has been shown in Fig. 10. It can be seen from the figures that the presence of another footing nearby, in fact, enhances the load-bearing pressure for close spacing. 
For all three soils, the single footing case gave the lowest value bearing pressure. For UR soil, the highest amount of bearing pressure was given for $\mathrm{SFD}=2 \mathrm{~B}$, after which there was no significant improvement. For GR soil, the maximum value was given for $\mathrm{SFD}=2 \mathrm{~B}$ and for PGR soil, the corresponding value was $\mathrm{SFD}=2 \mathrm{~B}$. Therefore, it observed that the adjacency of footings plays an essential role in enhancing the bearing pressure of a footing resting on sand overlying weak soil.

The reason for such results may be attributed to the fact that when $\mathrm{SFD}=\mathrm{B}$, the two foundations work as a single foundation, which results in an increased width and the resulting increase in bearing pressure. As the distance increases, the soil between the two foundations gets locked up and goes down with the foundation and thus behaving like a single unit. This event is related to the formation of an inverted arch beneath closely spaced strip footings, which is called "blocking"' as mentioned by other researchers. Therefore, the level of soil stress is increased in this zone by an increase in the load applied to the foundations. Since the stress cannot flow square footings, the stress is concentrated at the edges of the footings and a block is formed in the confined soil between the foundations. This phenomenon results in the formation of a rigid confined block in the space between the square and the strip footings and increases the loadbearing pressure. But with further increase in distance, the stresses are relieved and the foundations cease to affect the soil in between and thus giving lesser values of bearing pressure. The combined graph for normalized settlement vs. bearing pressure (Fig. 10) shows the maximum improvement for PGR soil as expected. It can be noticed that for UR soil, the increase was seen up to $\mathrm{SFD}=\mathrm{B}$ for $\mathrm{GR}$ soil $\mathrm{SFD}=2 \mathrm{~B}$ and also for $\mathrm{PGR}$ soil $\mathrm{SFD}=$ $2 \mathrm{~B}$ which proves the point that due to prestressing the enhanced support of the geogrid layer had resulted in the increased spacing of adjacent footings. The same can be understood more clearly from the bar charts provided for UR, GR and PGR soil in Fig. 11 for an initial small settlement. Therefore, it is inferred that placing two adjacent square footing increases the interference zone of PGR soil by $67 \%$ as compared to UR soil.

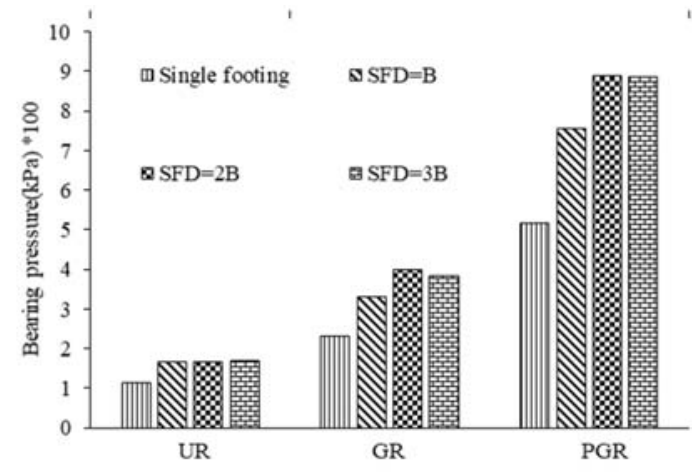

Fig. 11.Variations of bearing pressure for $1 \mathrm{~mm}$ of settlement considering different SFD values for UR, GR, and PGR soil.

\section{Conclusions}

In this study, the effect of prestressing a geogrid layer on the performance of a overlying square footing is studied. It is observed that on prestressing the geogrid, the membrane effect is mobilized at a minimal deformation. This membrane effect helps in settlement reduction and bearing capacity increment. It has also been observed that the total energy requirement of PGR soil is around 16\% of the unreinforced soil and almost $50 \%$ of the conventional geogrid reinforced soil. The studies on the effects of depth, size, and interference of footing take into account the practical implementation of prestressed geogrid reinforcement on the site. The results are highly encouraging and beneficial and can be adopted as an alternative to other uneconomical and cumbersome ground improvement techniques. At the same time, this method is extremely energy efficient while it significantly reduces the required settlement for geogrid tension mobilization simultaneously. The major constraint of choosing this technique for real scale field studies is the lack of suitable methodology of exerting the required prestressing force in the field.

Nonetheless, a few successful prestressing techniques have been reported in the past, however, a robust prestressing method is the need of the hour. This study is also highlighting that with the modern technology and development of appropriate prestressing techniques, the application of prestressed geogrid in the geotechnical field will scale up its probable use in the near future for a sustainable development.

\section{References}

1. Patra, C.R., Das, B.M., Atalar, C.: Bearing capacity of embedded strip foundation on geogrid-reinforced sand. Geotext. Geomembranes. 23, 454-462 (2005)

2. Andrawes, K.Z., McGown, A., Wilson-Fahmy, R.F., Mashhour, M.M.: The finite element method of analysis applied to soil-geotextile systems. In: Proc. of Second lnt. Conf. of Geotextiles. pp. 695-700. , Las Vegas, USA (1972)

3. Khing, K.H., Das, B.M., Puri, V.K., Yen, S.C., Cook, E..: Foundation on strong sand underlain by weak clay with geogrid at the interface. Geotext. Geomembranes. 13, 199-206 (1994)

4. Latha, G.M., Somwanshi, A., Latha, M.G., Somwanshi, A.: Bearing capacity of square footings on geosynthetic reinforced sand. Geotext. Geomembranes. 27, 281-294 (2009). doi:10.1016/j.geotexmem.2009.02.001

5. Sitharam, T.G., Sireesh, S.: Model studies of embedded circular footing on geogridreinforced sand beds. Proc. ICE - Gr. Improv. 8, 69-75 (2004)

6. Das, S.K., Samadhiya, N.K.: Numerical modelling of prestressed geogrid reinforced soil for adjacent square footing. In: Geo-Chicago 2016. pp. 827-835 (2016)

7. Gray, D.H., Al-Refeai, T.: Brhavior of fabric versus fiber reinforced sand. J. Geotech. Eng. ASCE. 113, 541-542 (1986) 
8. Das, B.M.: Shallow foundation on sand underlain by soft clay with geotextile interface. Geosynth. Soil Improv. 1, 203-214 (1988)

9. Ayyar, T.S.R., Krishnasamy.N.R., Ravishankar, S., Parashar, S.P.: Bearing capacity of kaolinite clay reinforced with geosynthetics. In: Proceedings of Indian Geotechnical Conference. pp. 11-14. , Bombay, India (1990)

10. Love, J.P., Burd, H.J., Milligan, G.W.E., Houlsby, G.T.: Analytical and model studies of reinforcement of a layer of granular fill on soft clay subgrade. Can. Geotech. J. 24, 611-622 (1987)

11. Madhav, M.R., Poorooshasb, H.B.: A new model for geosynthetic reinforced soil. Comput. Geotech. (1988). doi:10.1016/0266-352X(88)90070-5

12. Guido, V.A., Biesiadecki, G.L., Sullivan, M.J.: Bearing capacity of a geotextilereinforced foundation. In: Proc. of 11th International Conference on SMFE. pp. 1777-1780. , San Francisco, USA (1985)

13. Koerner, R.M.: Designing with geosynthetics. 6th Ed. 1, (2012). doi:10.1017/CBO9781107415324.004

14. Broms, B.B.: Design of fabric reinforced retaining structures. In: Proceedings of the Symposium on Earth Reinforcement, DSCE Special Convention. pp. 282-304. , Pittsburg, USA (1972)

15. Aboshi, H.: Soil improvement techniques in japan. In: Proc. of Seminar on Soil Improvement and Construction Techniques in Soft Ground. pp. 3-16. , Singapore (1984)

16. Shukla, K., Chandra, S.: A Generalized Mechanical Model for Geosynthetic-Reinforced Foundation Soil. Geotext. Geomembranes. 13, 813-825 (1995)

17. Shukla, S.K., Chandra, S.: The Effect of Prestressing on the Settlement Characteristics of GeosyntheticReinforced Soil. Geotext. Geomembranes. 13, 531543 (1994). doi:10.1016/0266-1144(94)90063-9

18. Lovisa, J., Shukla, S.K., Sivakugan, N.: Behaviour of prestressed geotextile-reinforced sand bed supporting a loaded circular footing. Geotext. Geomembranes. 28, 23-32 (2010). doi:10.1016/j.geotexmem.2009.09.002

19. Shivashankar, R., Jayaraj, J.: Behaviour of Prestressed Geosynthetic Reinforced Granular Beds Overlying Weak Soil. Indian Geotech. J. 44, 26-38 (2014). doi:10.1007/s40098-013-0070-6

20. Lackner, C., Bergado, D.T., Semprich, S.: Prestressed reinforced soil by geosynthetics concept and experimental investigations. Geotext. Geomembranes. 37, 109-123 (2013)

21. Huesker Synthetic: A 143 motorway Western relief road Halle/Germany. , Gescher, Germany (2004)

22. Chew, S.H., Tan, S.A., Leong, K.W.: Performance of geotextile stabilized unpaved road systems subjected to pretensioning. In: Geo-Frontiers Congress 2005. pp. 1-14 (2005)

23. Brinkgreve, R.B.J., Engin, E., Swolf, W.M.: Plaxis 3d 2013. Plaxis bv. 2013 (2013)

24. Aswathy, M.H., Jayamohan, J., Shivasankar, R.: Behaviour of Prestressed Geosynthetic Reinforced Granular Bed Overlying Weak Soil. In: Proceedings of Indian Geotechnical Conference. , Roorkee.India
(2013)

25. Aswathy, M.S., Shivashankar, R., Jayaraj, J.: Behaviour of Prestressed Geosynthetic Reinforced Granular Beds Overlying Weak Soil. In: Indian Geotechnical Conference. pp. 1-8. , Roorkee.India (2013)

26. Sharma, R., Chen, Q., Abu-Farsakh, M., Yoon, S.: Analytical modeling of geogrid reinforced soil foundation. Geotext. Geomembranes. 27, 63-72 (2009). doi:10.1016/j.geotexmem.2008.07.002

27. Shivashankar, R., Jayaraj, J.: Effects of prestressing the reinforcement on the behavior of reinforced granular beds overlying weak soil. Geotext. Geomembranes. 42, 69-75 (2014). doi:10.1016/j.geotexmem.2013.08.008 